\title{
Developing English Pronunciation through Animation and YouTube Videos
}

\author{
Muayyed J. Juma \\ Translation Department \\ Al-Ma'moon University College \\ Baghdad-Iraq \\ Email: Muayyed.j.juma@almamonuc.edu.iq
}

Received: 8/3/2021 Accepted: 11/14/2021 Published:12/15/2021

\begin{abstract}
Using multimedia inside the English as a foreign language (EFL) lassroom has been anticipated by several researchers and educators recently as a new necessary component of language learning. This is ascribed on the one hand to the continuous advancements in the new technological devices that might be used in presenting the various types of multimedia inside the classroom, and, on the other hand, to the fact that learners have started to acquire new modes of cognitive learning preferences due to their excessive daily use of these devices. This study investigates the appropriateness and practicality of using some animated or dynamic graphs and YouTube movies in teaching the pronunciation of English to Iraqi-Arabic learners of English as a foreign language. The two groups of the subjects who participated in this case study were taught using two different methods of teaching with and without using multimedia. Unlike those who were part of the control group, subjects belonging to the experimental group performed much better in their posttest results $(62.31 \%$ of the experimental group average percentage and $47.09 \%$ of the control group average percentage).
\end{abstract}

Keywords: Animation, EFL teaching, English pronunciation, multimedia, YouTube videos

Cite as: Juma, M. J. (2021). Developing English Pronunciation through Animation and YouTube Videos. Arab World English Journal, 12 (4) 142-152.

DOI: https://dx.doi.org/10.24093/awej/vol12no4.26 


\section{Introduction}

Although there has been a considerable timespan since the communicative approach to English language teaching was first proposed, both teachers and students in many non-native English- language speaking countries, including Iraq are still not able to adapt it as a teaching style due to several educational and technical reasons such as the unavailability of native English teachers and the lack of classrooms with the required equipment. As it is universally known, the main elements of this approach are exposing the foreign learners to as many authentic materials as possible and using them interactively inside and outside the language classroom. The learning strategies used by the students in these countries in learning English language are similar to those used in learning any other subject matter as their main aim is to pass the exams. Accordingly, generally speaking, the students find the whole process of learning as monotonous and unfruitful. Due to the continuous advancements in the new technology, the last three decades have witnessed a new generation of learners in general and EFL learners in particular. The hallmark of this generation is the skillful use of interactive computer-mediated technologies such as smartphones, laptops, and iPads to create and share their interests and ideas in highly-complex virtual communities and networks. This global social phenomenon has created new modes of thinking and learning and recalled the communicative approach to be an integrated part of any EFL classroom.

Prensky (2001) calls this generation the "digital immigrants"; a term which was basically introduced in 1996 after the declaration of the independence of cyberspace (Zaphiris \& Ioannou 2018). People who belong to this generation all around the world share several characteristics. Apart from the professional use of various types of new technological devices and their countless applications, they have changed to be more like active learners and interactive users, though virtually, in collecting information and distributing news on the Internet. As for learners of English as a foreign language, Benson (2015) thinks that these new technological devices lead to a new era of "intercultural interaction" which would naturally require us to think of new techniques and procedures in English teaching.

Such remarkable development of the technological devices and the new modes of learning have encouraged teachers and educators to think about how to make use of them in the academic setting. For instance, some scholars investigated what they call game-based learning talking about the cognitive advantages of playing games Van Eck (2006). Gee (2005) assumes that the game player is also a learner and a "co-designer" who learns how to make decisions and solve problems and construct an imagination. On the other hand, several scholars investigated the use of multimedia inside the EFL classroom. Yudintseva (2015) surveyed seventeen published studies that examined whether computer games and videos might help in developing the learning strategies concluding that "interactions with native speakers in anonymous informal gaming environment reduced anxiety and increased exposure to slang and colloquial language" (p.107).

\section{Literature Review}

\section{Animation inside EFL Classroom}

Multimedia is usually understood as an amalgamation of texts, sounds, pictures, animation and videos which are used interactively to entertain. The term was first used in art by Bob Goldstein; a British singer and artist as a means to develop his performance (Badii et. al.: 2009). Mayer and Moreno (2002) have defined multimedia in terms of the two channels through which the user 
perceives it (visual and auditory), the modes used to transfer it (pictorial and verbal), and the devices used in multimedia presentation (computers, laptops, iPads, etc.). As one technique of multimedia demonstration, animation is usually understood as the process of manipulating pictures in a moving presentation. It started by hand painting pictures which then photographed and transformed into movies. As a result of the development of technological devices that might be used in this reference, we now have sophisticated computer animation and 3D animation.

Animation, which is one of the most important forms of multimedia these days, has been identified with three main features: they are represented by pictures (whether hand painted or computerized), they are not real pictures, and non-static (Mayer \& Moreno: 2002)

Despite the fact that the various forms of multimedia including animation were basically used for entertainment, the fascinating development in the technological devices used and its widespread among the new generation have stimulated teachers and educators to use a comparative technique inside the classroom.

In order to differentiate between animation in its entertaining and teaching dimensions, Lowe (2004) proposes four different roles that might be assigned to it. The first one is called "affective" which carries the enjoyable function that motivates the receivers' sensations, whereas the "cognitive" role is associated with comprehending a specific message implied in the subject matter, the third one is an "enabling" role which might be used by learners who have some difficulty in understanding the subject matter, and the fourth one is a "facilitative" one which is used when learners have already acquired the required information and need more explanation and illustration. Even though the first function of animation suggested by Lowe represents its unmarked characteristic as it was basically invented to entertain, investigating the nature of the other three functions is naturally our main concern in this paper.

Talking about the cognitive function of animation requires us to think of animated graphics rather than pictures as the term is usually used with the implicature of informing and illustrating more than entertaining. Tversky, Morrison, \& Betrancourt (2002) try to answer the question if graphics (whether static like maps and building plans or dynamic ones like cartoon movies) "can facilitate comprehension, learning, memory, communication and inference". They found that although the animated graphics carry more sophisticated system of information in comparison to static ones, they are less comprehensible because of this exact feature. Yet, other scholars such as (Caraballo, 1985, Rieber, 1996 \& Wong, 1994) assert that dynamic or "animated visualization is more likely than static visuals to present effectively movement inpreceptible to the human eye"

Mayer (2005) proposes a theory of multimedia learning after 15 years of collaborative work at University of California that might help to explore the nature of the "instructional messages" within multimedia and how they are transformed and perceived. The theory is based on five "cognitive processes": "Selecting relevant words from the text or narration, selecting relevant images from the illustration, organizing the selected words into a coherent verbal representation, organizing the selected images, and integrating the pictorial and verbal representations and prior knowledge". The theory, moreover, is based on three different assumptions: The first is the "dual-channel assumption" based on the fact that the learners perceive information via ears or eyes depending on the nature of information (e.g. words and narration vs. animations and videos), the second is the "limited-capacity" of learners in "storing the amount of information in each channel", and the third is the "active-processing" of 
information which is concerned with "integrating the new with prior knowledge" (Mayer,2005, pp. 31-58).

As it is obvious, the theory talks about general learning via all types of multimedia differentiating between static and dynamic graphics on one hand, and the implied nature of the information (i.e. verbal or visual) in whatever multimedia type is used. Two questions are to be raised in this reference. First, how does the theory work in language processing? And second, does the theory work in learning English as a foreign language in a comparative way? In order to answer these two questions, a modified version of the theory might be presented to be more applicable to learning English as a foreign language (see Figure 1).

The major difference is the obstacles that exist in the long-term memory concerning the first language phonological, syntactic, and semantic structures which stop the integration between the prior knowledge and new knowledge and confuse the organization of words and images in the working memory. To illustrate, if an Arab learner of English as a foreign language hears and watch the word "strawberry" through a dynamic graph, he would process its pronunciation and meaning by using his auditory and visual channel and store it in his working memory. Yet, when connecting it to his prior knowledge in the long-term memory which in this case reads there is no consonant clusters in Arabic, there will be a confusion in the working memory as the pronunciation of the word would be stored as /sitro:beri/ instead of /stro:bər.i/. Such confusion would most likely disorganize the sounds and probably also the images if we put in mind the homophonous words.

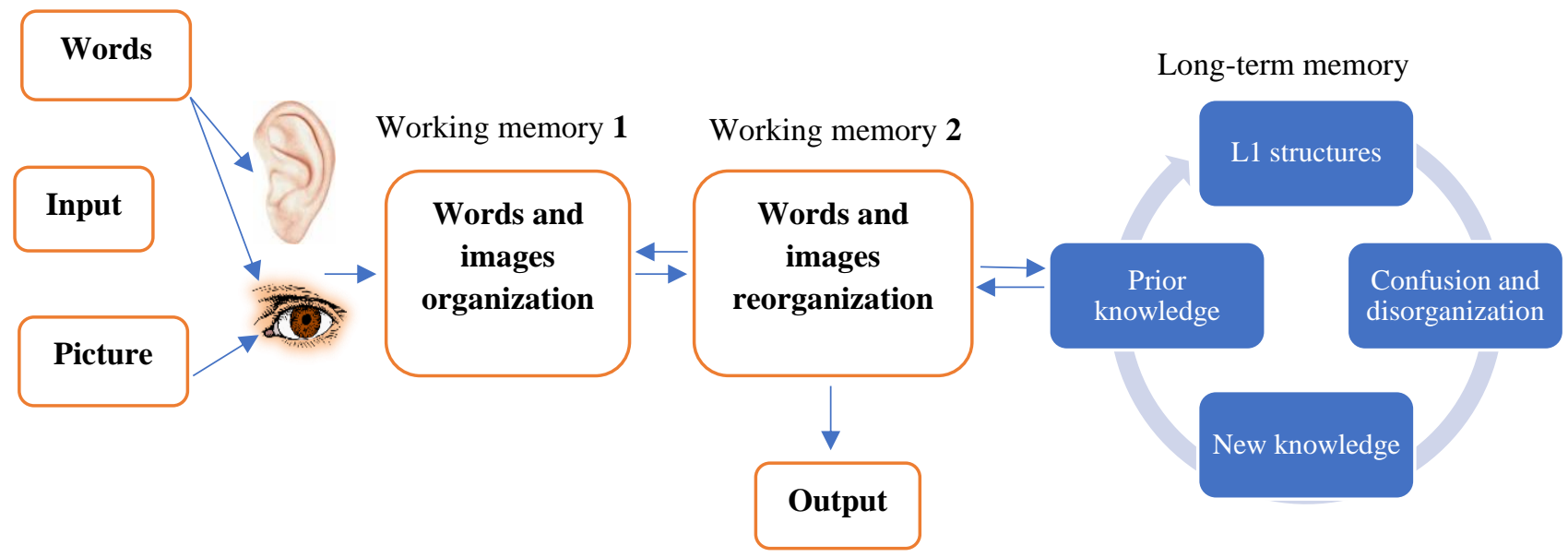

Figure 1. The Multimedia Learning of a Foreign Language Based on Mayer (2005, pp. 31-58)

\section{YouTube Videos inside EFL Classroom}

In addition to animation, the web. 2 generation has shown a great interest in using the YouTube movies. Benson (2015) believes that the gradual universal spreading of technological devices like smartphones, laptops, iPads, etc., helped the new generation to have their own say in using the social media applications such as Facebook, Twitter, and YouTube lead to a new era of intercultural interaction. According, as they do with animation, teachers and educators particularly in EFL setting all around the world started to study how to make use of this universal phenomena inside the classroom. 
One of the most important advantages of using YouTube movies as an educational tool inside the EFL classroom is to provide learners with the chance to listen to authentic material. Felix (2002) and O'Dowd (2000), Bastos \& Ramos (2009) assume that "the use of authentic learning materials that engage second language learners to communicate in real contexts and foster the development of comprehension and communication (oral and writing) skills and intercultural communication competences, plays a crucial role in foreign language learning". Stempleski (1995), states that "English teachers all over the world cry out for materials which can make English come alive for their students. TV, video, and the newer-video related technologies provides just such a resource". Other scholars such as (Çakir, 2006) connect between the need to revive the communicative approach to English language learning and this need to use authentic material inside the EFL classroom.

Apart from the exposure to authentic materials as a main advantage of using YouTube videos inside the EFL classroom, other scholars discuss some other ideas. Arthur (1999) talks about developing the audio/visual perceptions of learners and increasing the awareness of the FL culture, and providing teachers with different alternatives to control the learners' anxiety. Berk (2009), moreover, adds some other advantages related to motivating learners by attracting their attention, increasing their comprehension and memorization, and providing them with a great opportunity to express themselves spontaneously. Moreover, Harmer (2001) found two logics behind incorporating videos with the learning process. First, enhancing the learner's comprehension as the visual clues implied would help to transform both meanings and moods. Second, raising the cultural awareness of learners by making an association with the real contexts outside the classroom.

Despite these advantages some scholars such as (Olson \& Clough: 2001) talk about a "caution not". When using YouTube movies inside the classroom as they might overburden the learners with the overwhelming information that exceeds their conceptual comprehension. In the same reference, Rachelle \& Heller (1990) discuss the problem of information abundance in cyberspace that might confuse learners and prevent them from arriving at the main content of the intended message. Hoogeveen (1997), moreover, denies the existence of clear evidence for the practicality of using multimedia in learning as it leads to "negative cognitive side effects" such as overstimulation, cognitive overload, and fatigue.

Regardless of such warning notes about using YouTube movies inside EFL classroom, when the web. 02 generation will have the lead as teachers and educators in the near future, it is universally expected that nothing would prevent them from using all types of technological devices inside the classroom as they would be part of their learning life.

\section{Teaching English Pronunciation to Foreign Learners: How to Overcome the Negative Effect of L1 Sound System?}

Courses designed to teach English pronunciation at the under-graduate level usually include the following four topics:

- short introduction to the difference between phonetics and phonology,

- detailed account to the articulators or organs of speech as the main topic of "articulatory phonetics"

- detailed account to the English consonants, vowels, and diphthongs, 
- summarized discussion to some English phonological issues like, stress and intonation, assimilation, and consonant clusters.

There are various challenges concerning learning the correct pronunciation of English by foreign language learners. One of the most prominent challenges is how to overcome the effect of the first language. Advanced foreign learners of English might succeed in acquiring a native-like competence in all aspects of the language skills but keeping the accent and some phonological habits of their mother tongue. Ellis (1994) states that "the existence of foreign accent in L2 learning is so well attested that it hardly requires documenting. In general, native speakers have little difficulty in distinguishing the language background of different learners" .To illustrate, he cites Purcell and Suter (1980) who asked native speakers of English to judge the "pronunciation accuracy" of foreign learners of English with four different L1 (Thai, Japanese, Arabic, and Persian) and found that although the pronunciation inaccuracy was clear in all the subjects, the Thai and Japanese learners were less accurate due to the language distance with English.

Back to Lado's contrastive analysis hypothesis (CAH) appeared in his book "Linguistics Across Cultures" (1957), one may find the best interpretation to the difficulty that foreign language learners find in learning the pronunciation of English. In the introduction, he states that:

the student who comes into contact with a foreign language will find some features of it quite easy and others extremely difficult. Those elements that are similar to his native language will be simple for him, and those elements that are different will be difficult $(\mathrm{P}$. 20).

Despite the fact that the CAH was subject to different types of criticism, it has proved to be very efficient in any foreign language classroom as it helps teachers to concentrate on the L1/L2 differences and accordingly design the appropriate syllable for their students.

To shed some light on the difficulty that an Arab learner finds in learning the English vowels and diphthongs, for instance, in the light of $\mathrm{CAH}$, one may recall that there are 27 vowels (short, long, diphthongs and triphthongs) in English, whereas in Arabic there are only three vowels (أاو/ي) whose function in the Arabic writing system as letters is far more prominent than their function in the sound system even for the Arabic native speakers. Consequently, we may expect that Arab learners would find a great deal of difficulty in learning the English vowels and diphthongs.

In order to mitigate the difficulty of learning the English pronunciation to a certain degree, phoneticians realized, long time ago, the importance of using the language labs making use of

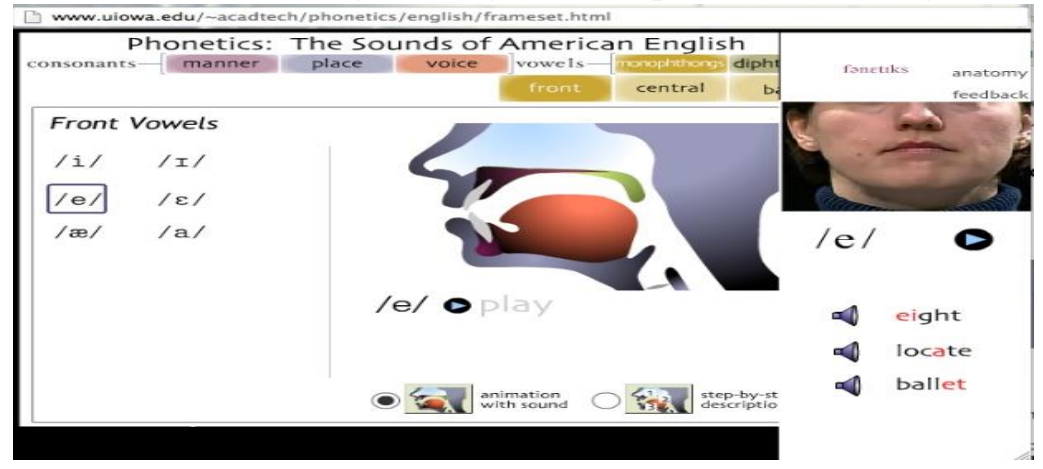

Figure 2. The University of Iowa Project of the Formation of the American English Sounds 
the available technological devices. Since the time of Daniel Jones (1881-1967) who was of the founders of the International Phonetic Association (IPA), scholars working in phonetics have been in a continuous pursuit of appropriate tools to help learners starting form cassette tape recorders in the 1960s and ending up the dynamic graphs, software, applications, and YouTube videos. To illustrate, a group of students at the University of Iowa developed computer software which later on became a smartphone application in App Store and Google Play in which they "provide a comprehensive understanding of how each of the speech sounds of American English, Spanish, and German are formed. It includes animations, videos, and audio samples that describe the essential features of each of the consonants and vowels of these languages".

Moreover, the IPA interactive chart has been developed by individual phoneticians, departments of linguistics and phonetics at different American and British universities, and different academic institutions such as the British Council making good use of the new technology. For instance, Paul Meier and Eric Armstrong developed a neat detailed demonstration to the IPA interactive chart with both American and British pronunciation and made it available at Tunes app and Android app.

In addition to these applications which have been used by thousands of foreign English learners in all around the world, there are enormous YouTube videos which are made available by several native English teachers that have been found very useful in providing an authentic English pronunciation to foreign learners.

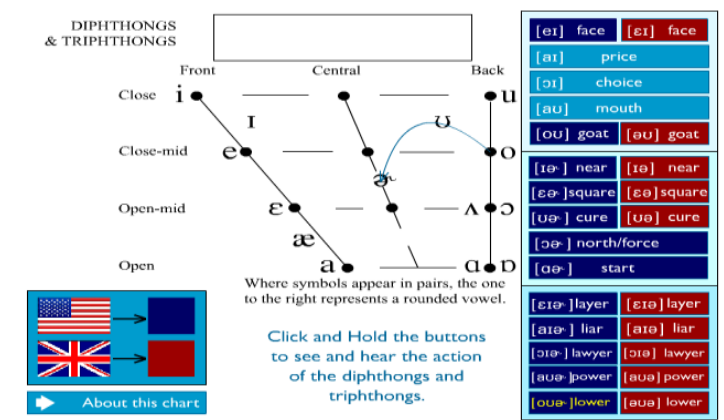

Figure 3. YouTube Educational Videos of English Pronunciation

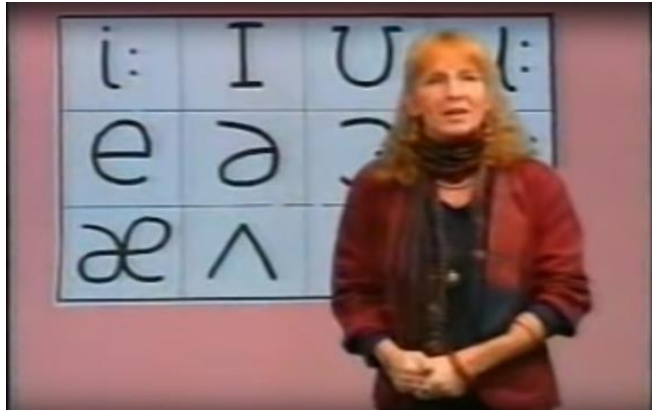

Figure 4. The IPA Interactive Chart Meier and Armstrong

\section{Methods}

The study aims to answer the following question:

- Does using animation and YouTube videos inside the EFL classroom in teaching English pronunciation to make any difference in comparison to the traditional method of teaching?

The subjects of the study were 44 second-year female students at the English department/ College of Education for Women/ Al-Iraqia University who share the same age with equivalent educational backgrounds despite some minor individual discrepancies.

Participants 
This study was implemented in the College of Education for Women at Al- Iraqia University in 2018-2019. The 44 students who participated in the study had a three-month course in which they studied articulatory phonetics (the functions of speech organs), the characteristics of consonants in terms of manner and place of articulation and voicing, the characteristics of vowels in terms of the vertical and horizontal movements of the tongue. They also studied the transcriptions of the English vowels and consonants with few examples for the sake of practice. In teaching how the consonants and vowels are pronounced, teachers usually read the examples aloud in the classroom after writing their transcriptions on the board asking some students to repeat over and over. After the course, the 44 students were subject to a pretest to assess their overall comprehension of the course. Then, they were divided into two groups; the control group (22 students) was provided with a three-hour lecture in which the teacher revised the pronunciation of the English vowels and diphthongs following the same traditional method based on imitation, memorization, and repetition using the textbook and the board. The experimental group was given a three-hour lecture in which another teacher revised the pronunciation of the English vowels and diphthongs using the interactive lab instead of the classroom. The experimental group revised the lecture with the help of the two applications and YouTube videos mentioned above. After the lecture the 44 students were admitted to a posttest.

\section{Discussing the Results}

The pretest results of the study (see the details in the Appendix A) of both the control and experimental groups were almost the same (the average percentage of the total scores was 54.2\% for the experimental group and $54.27 \%$ for the control group). These results helped to give a more accurate answer to the main question of the study. On the other hand, the average percentage of total scores of the posttest results of the experimental group was $(62.31 \%)$ which was much better than that of the control group (47.09) which indicate clearly the efficiency of using animation and YouTube videos. Figures (5 and 6) illustrate a comparison between the pretest and posttest results for each one of the 44 students in both groups. The rising and falling results when comparing the pretest and posttest in both groups as illustrated in Figures (7 and 8) support the same assumption. It should be mentioned here that to the best of the researcher's knowledge, there is no clear reason that explains the falling drop in the control group's results comparing with their own results in the pretest other than the timespan between finishing the three months course and doing the test (about a month).

Moreover, in order to have a more obvious idea about the results of the two groups in the posttest, a comparison made between the results related to answering the questions about vowels in comparison to diphthongs. Such comparison was made to see if there is a difficulty that the subjects might have in comprehending the pronunciation of particular groups of English vowels. As for the experimental group (Figures 9 and 10), the average percentage related to answering questions about vowels was $(62.27 \%)$, and (46.81\%) for the control group.

As for answering the questions related to diphthongs (Figures 11 and 12), the percentage of the experimental group was $(63.18 \%)$ and that of the control group was $(46.81 \%)$. These numbers support the main conclusion mentioned above about the superiority of the experimental group's performance. 
Arab World English Journal (AWEJ) Volume 12. Number 4. December 2021

Finally, there is no significance difference between the average percentage related to both vowels and diphthongs in the experimental group $(62.27 \%$ and $63.18 \%)$ consecutively.

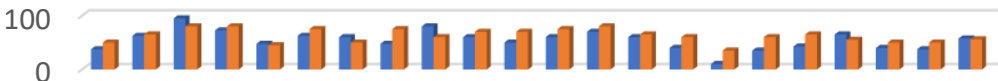 \\ $1 \quad 2 \quad 3 \quad 4 \quad 5 \quad 6 \quad 7 \quad 8 \quad 9 \quad 10111213141516171819202122$ \\ m pretest $\square$ posttest}

Figure 5. Experimental Group Pretest and Protest Results

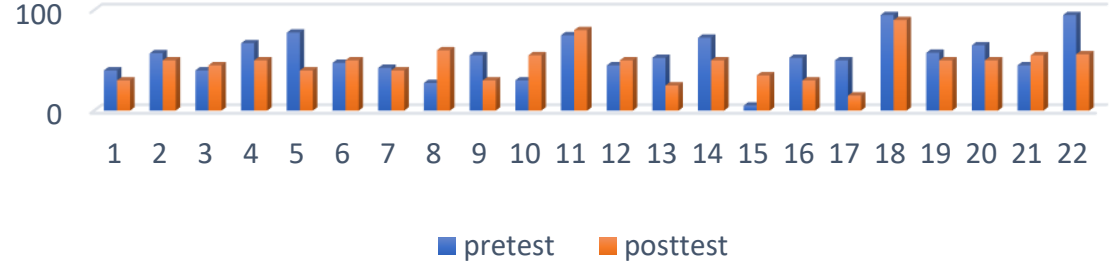

Figure 6. Control Group Pretest and Protest Results

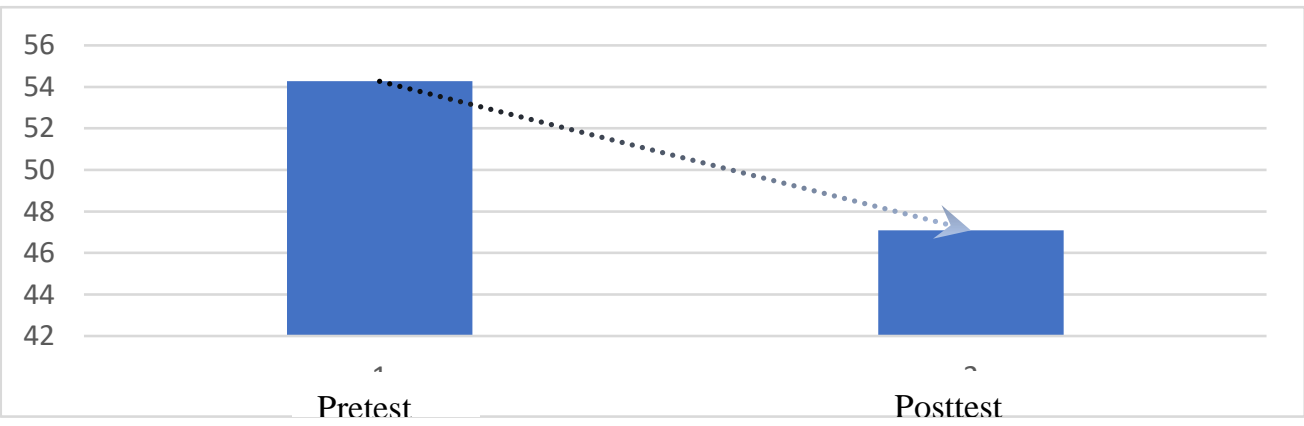

Figure 7. Percentages Comparison between Pretest and Posttest for the Control Group

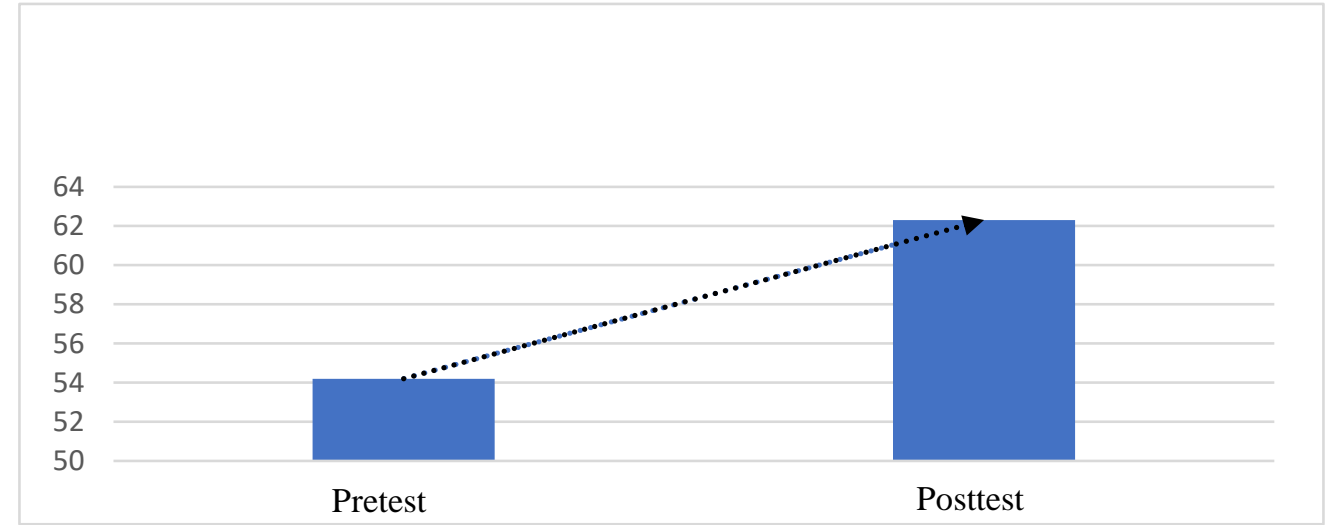

Figure 8. Percentages Comparison between Pretest and Posttest for the Experimental Group 
Arab World English Journal (AWEJ) Volume 12. Number 4. December 2021

Developing English Pronunciation through Animation and YouTube Videos

Juma

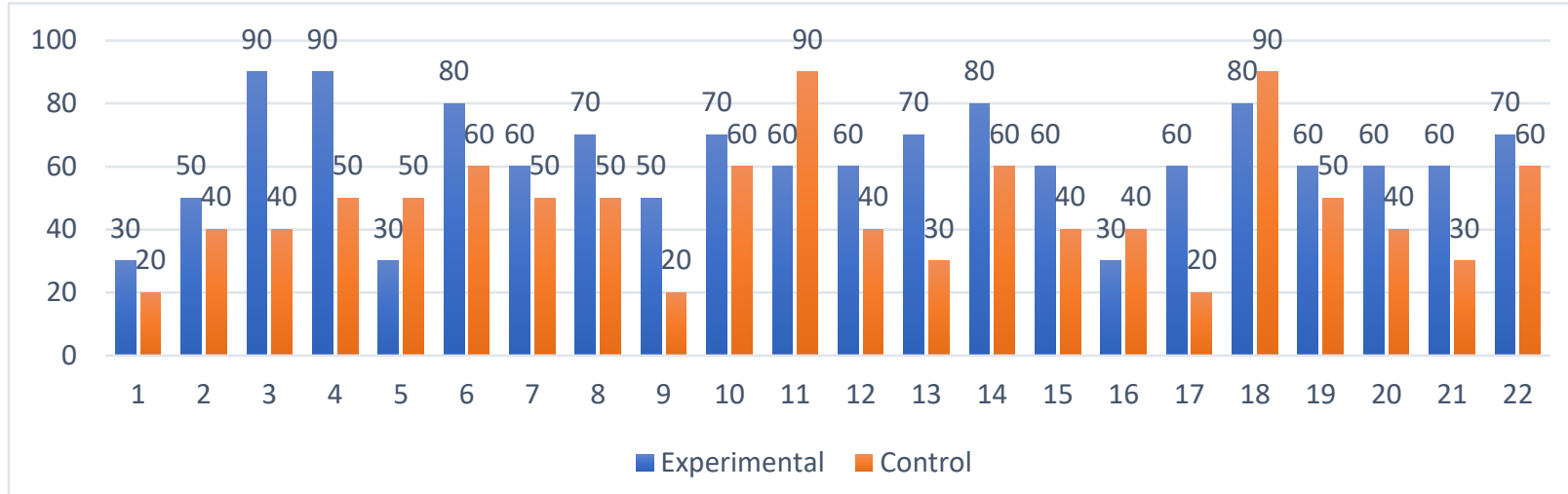

Figure 9. Vowels Results in Experimental and Control Groups

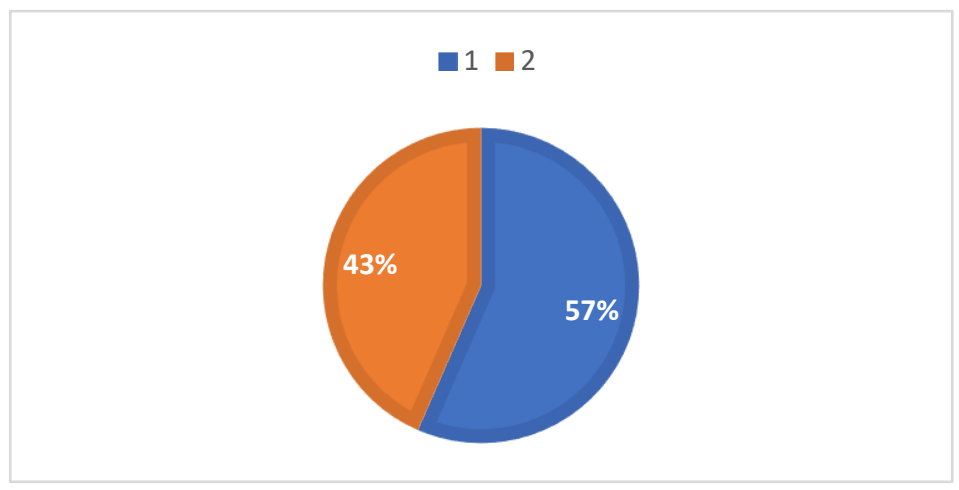

Figure 9. Vowels Percentages in Experimental and Control Groups

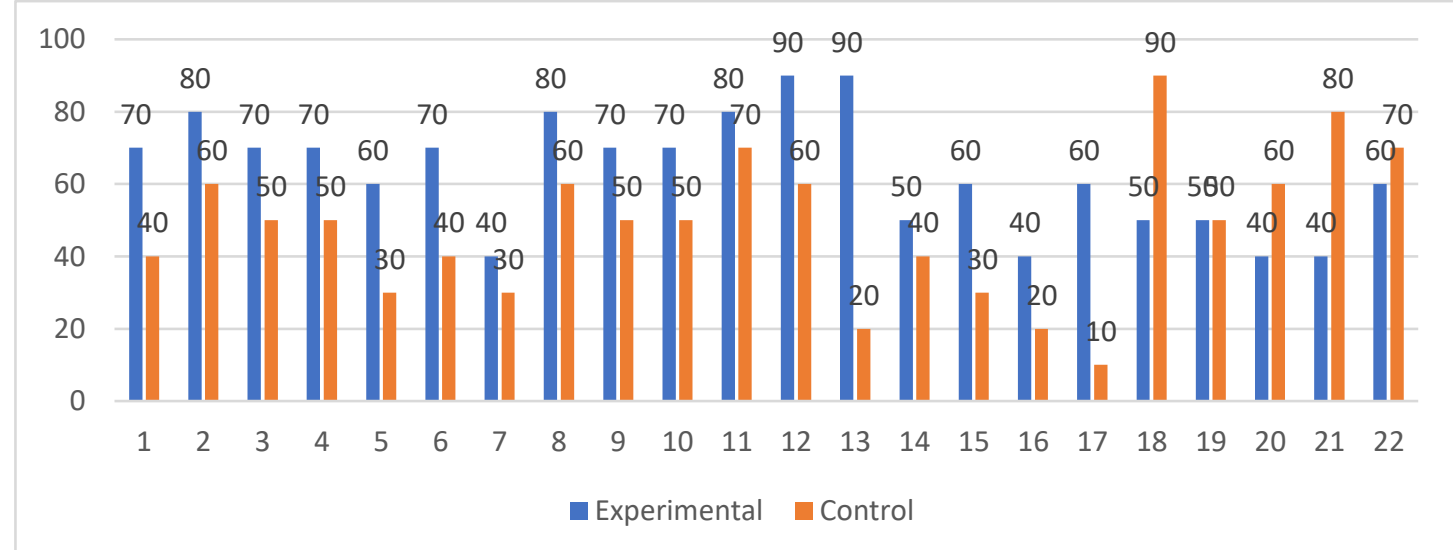

Figure 11. Diphthongs Results in Experimental and Control Groups 

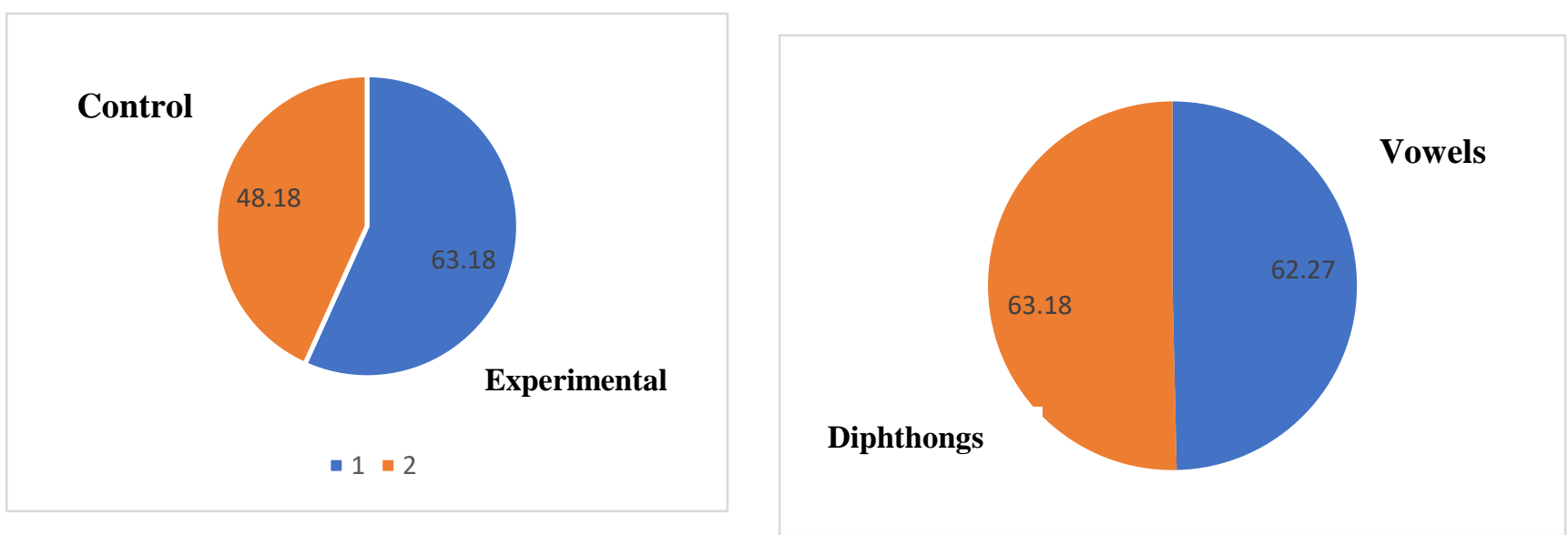

Figure 12: Diphthongs Percentages in Control and Experimental Groups

Figure 12: Vowels and Diphthongs Percentages in Experimental Groups

\section{Conclusion}

Teaching English pronunciation to FL learners has always been a challenge to non-native English teachers. In the last few years, the researcher has occasionally witnessed the presence of Iraqi students whose English pronunciation (mostly American accent) is sometimes more accurate than their teachers. This might be ascribed to the fact that the new generation of students has been linked, in one way or another to the Web.2.0 users, whereas their teachers, generally speaking, are outside this domain. As the Web.2.0 Iraqi young people use the same technological devices and applications used in the entire world to have a direct access to the same social media cites, they have developed their own English pronunciation before they join their regular study. The new experience of on-line university teaching and learning that we are witnessing these days due to Coronavirus spread has proved the importance of thinking of making a good use of the available technological devices and applications.

Yet, those teachers planning to make use of these devices and applications inside the classroom in both face-to-face and virtual interactions should take into their considerations the possible negative side effects such as overstimulation, cognitive overload, and fatigue.

\section{About the Author:}

Asst. Prof. Muayyed J. Juma. I had my bachelor, Master, and Ph.D. degrees from Baghdad University in English language and linguistics and worked as an English teacher in different universities in Iraq, Jordan, and Oman for almost 20 years. I am working now in Al Mamoun University College in Baghdad.

\section{References}

Arthur, P. (1999). Why Use Video? A Teacher's Perspective. VSELT 2 (4) Bechman, Lyle. F.

Badii, A., Fuschi, D., Khan, A., \& Adetoye, A. (2009-11-09). Accessibility-by-Design: A Framework for Delivery-Context-Aware Personalized Media Content Re-purposing. HCI and Usability for E-Inclusion. Lecture Notes in Computer Science. Springer, Berlin, Heidelberg. pp. 209-226. 
Bastos, A., \& Ramos, A. (2009). YouTube for Learning English as a Foreign Language: Critical Thinking, Communicative Skills. Proceedings of EDULEARN09 Conference. 6th-8th July 2009, Barcelona, Spain.

Benson, B. (2015). Commenting to Learn: Evidence of Language and Intercultural Learning in Comments on YouTube Videos. Language Learning and Technology, 19(3), 88-105.

Benson, B. (2015). Commenting to Learn: Evidence of Language and Intercultural Learning in Comments on YouTube Videos. Language Learning and Technology, 19(3), 88-105.

Berk, R. A. (2009). Multimedia Teaching with Video Clips: TV, Movies, YouTube, and MtvU" in the College Classroom. International Journal of Technology in Teaching and Learning, 5(1), 1-21.

ÇAKIR, I. (2006). The Use of Video as an Audio-Visual Material in Foreign Language Teaching Classroom. The Turkish Online Journal of Educational Technology - TOJET, 5(4).

Caraballo, A. (1985). An Experimental Study to Investigate the Effects of Computer Animation on the Understanding and Retention of Selected Levels of Learning Outcomes, (Unpublished Doctoral Dissertation). The Pennsylvania State University: State College, PA.

Ellis, R. (1994). The Study of Second Language Acquisition. Oxford: Oxford University Press.

Felix, U. (2002). The Web as a Vehicle for Constructivist Approaches in Language Teaching. $\operatorname{ReCALL}, 14$ (2), 2-15.

GEE, J. P. (2005). Learning by Design: Good video games as learning machines. E-Learning, 2(1).

Harmer, J. (2001). The Practice of English Language Teaching. Essex, England: Longman.

Hoogeveen, M. (1997). Toward a Theory of the Effectiveness of Multimedia Systems. International Journal of Human-Computer Interaction, 9(2), 151-168.

Lado, R. (1957). Linguistics across Cultures. Ann Arbor: University of Michigan Press.

Lin, H. (2007). Reading Authentic EFL Text Using Visualization and Advance Organizers in a Multimedia Learning Environment. Language Learning \& Technology, 11(3) 83-106.

Lowe, R. (2004). Interrogation of a dynamic visualization during learning. Learning and Instruction, 14 (3), 257-274.

Mayer, R. (2005). Cognitive Theory of Multimedia Learning. In R. Mayer (Ed.), The Cambridge Handbook of Multimedia Learning (pp. 31-48). Cambridge: Cambridge University Press. Mayer and Moreno.

O’Dowd, R. (2000). Intercultural Learning Via Videoconferencing: A Pilot Exchange Project, in ReCALL, 12 (1), 49-61.

Olson, J. K., \& Clough, M. P. (2001). Technology's Tendency to Undermine Serious Study: A Cautionary Note. The Clearing House, 75, 8-13.

Prensky, M. (2001). Digital Natives, Digital Immigrants, Part 1. The Horizon, 9, 3-6. http://dx.doi.org/10.1108/10748120110424816.

Purcell, E., \& Suter, R. (1980). "Predictors of Pronunciation Accuracy: A Reexamination", in Language Learning, 30, 271-287.

Rachelle S. H. (1990). "The Role of Hypermedia in Education”, in Journal of Research on Computing in Education, 22 (4), 431-441. 
Rieber, L. P. (1996). "Animation as Feedback in a Computer-based Simulation: Representation Matters", in Educational Technology, Research and Development, 44(1), 5-22.

Stempleski, S. (1995). The Role of Video in Language Teaching in the Second Annual Convention (pp. 48-49). Nizhny Novgorod, Russia: Nizhny Novgorod English Language Teachers Association (NNELTA).

Tversky, B., Morrison, J. B., \& Betrancourt, M. (2002). Animation: Can it facilitate? International Journal of Human-Computer Studies, 57, 247-262.

Van Eck, R. (2006). Digital Game Based Learning. It's Not Just the Digital Natives Who Are Restless. Educause, 41(2).

Wong, A. Y. K. (1994). The Use of Animation in Computer-Assisted Instruction, (Unpublished doctoral dissertation). Carleton University: US.

Yudintseva, A. (2015). Game-enhanced Second Language Vocabulary Acquisition Strategies: A Systematic Review. Open Journal of Social Sciences. 10.4236/jss.2015.310015.

Zaphiris, P., \& Ioannou, A. (2018). Learning and Collaboration Technologies. Learning and Teaching. Proceedings of the 5th International Conference, LCT 2018, Held as Part of HCI International. Las Vegas, NV, USA, July 15-20.

\section{Appendices}

\section{Appendix A}

The Results of the Study

\begin{tabular}{|l|l|l|l|l|l|l|l|l|}
\hline $\begin{array}{l}\text { N } \\
\text { o. }\end{array}$ & $\begin{array}{l}\text { Experimen } \\
\text { tal pretest }\end{array}$ & $\begin{array}{l}\text { Experimen } \\
\text { tal posttest }\end{array}$ & $\begin{array}{l}\text { Contr } \\
\text { ol } \\
\text { pretes } \\
\text { t }\end{array}$ & $\begin{array}{l}\text { Contr } \\
\text { ol } \\
\text { postte } \\
\text { st }\end{array}$ & $\begin{array}{l}\text { Experimen } \\
\text { tal posttest } \\
\text { vowel }\end{array}$ & $\begin{array}{l}\text { Experimen } \\
\text { tal posttest } \\
\text { diphthong }\end{array}$ & $\begin{array}{l}\text { Contr } \\
\text { ol } \\
\text { postte } \\
\text { st } \\
\text { vowel }\end{array}$ & $\begin{array}{l}\text { Control } \\
\text { posttest } \\
\text { diphtho } \\
\text { ng }\end{array}$ \\
\hline 1 & 37.5 & 50 & 40 & 30 & 30 & 70 & 20 & 40 \\
\hline 2 & 62.5 & 65 & 57 & 50 & 50 & 80 & 40 & 60 \\
\hline 3 & 95 & 80 & 40 & 45 & 90 & 70 & 40 & 50 \\
\hline 4 & 72.5 & 80 & 67 & 50 & 90 & 70 & 50 & 50 \\
\hline 5 & 47.5 & 45 & 77.5 & 40 & 30 & 60 & 50 & 30 \\
\hline 6 & 62.5 & 75 & 47.5 & 50 & 80 & 70 & 60 & 40 \\
\hline 7 & 60 & 50 & 42.5 & 40 & 60 & 40 & 50 & 30 \\
\hline 8 & 47.5 & 75 & 27.5 & 60 & 70 & 80 & 50 & 60 \\
\hline 9 & 80 & 60 & 55 & 30 & 50 & 70 & 20 & 50 \\
\hline 10 & 60 & 70 & 30 & 55 & 70 & 70 & 60 & 50 \\
\hline 11 & 50 & 70 & 75 & 80 & 60 & 80 & 90 & 70 \\
\hline 12 & 60 & 75 & 45 & 50 & 60 & 90 & 40 & 60 \\
\hline 13 & 70 & 80 & 52.5 & 25 & 70 & 90 & 30 & 20 \\
\hline 14 & 60 & 65 & 72.5 & 50 & 80 & 50 & 60 & 40 \\
\hline 15 & 40 & 60 & 5 & 35 & 60 & 60 & 40 & 30 \\
\hline 16 & 10 & 35 & 52.5 & 30 & 30 & 40 & 40 & 20 \\
\hline 17 & 35 & 60 & 50 & 15 & 60 & 60 & 20 & 10 \\
\hline
\end{tabular}


Arab World English Journal (AWEJ) Volume 12. Number 4. December 2021

\begin{tabular}{|l|l|l|l|l|l|l|l|l|}
\hline 18 & 42.5 & 65 & 95 & 90 & 80 & 50 & 90 & 90 \\
\hline 19 & 65 & 55 & 57.5 & 50 & 60 & 50 & 50 & 50 \\
\hline 20 & 40 & 50 & 65 & 50 & 60 & 40 & 40 & 60 \\
\hline 21 & 37.5 & 50 & 45 & 55 & 60 & 40 & 30 & 80 \\
\hline 22 & 57.5 & 56 & 95 & 56 & 70 & 60 & 60 & 70 \\
\hline $\mathbf{T}$ & 1192.5 & 1371 & 1194 & 1036 & 1370 & 1390 & 1030 & 1060 \\
\hline $\mathbf{M}$ & 54.2 & 62.31 & 54.27 & 47.09 & 62.27 & 63.18 & 46.81 & 48.18 \\
\hline
\end{tabular}

Appendix 2: The Posttest Questions

Circle the correct answer among the following alternatives:

1. The vowel [i:] appears in the following word:
A. retch
B. beat
C. bad
D. wet

2. The vowel [I] appears in the following word:
A. led
B. bead
C. reach D. bid

3. The vowel [e] appears in the following word:

A. rich $B$. bat C. $\tan D$. bed

4. The vowel [a] appears in the following word:

A. pun B. mesh C. dad D. dud

5. The vowels $[\boldsymbol{\Lambda}]$ appears in the following word:

A. ton B. dead C. mash D. bat

6. The long vowel [a:] appears in the following word:

A. lust B. barks C. cop D. duck

7. The vowel [o] appears in the following word:

A. luck B. carp C. cop D. barks

8. The vowel [ə] appears in the following word:

A. know B. Now C. attend d. loud

9. The long vowel [3:] appears in the following word:

A. pull B. pool C. heard D. pilot

10. The long vowel [o:] appears in the following word:

A. shod B. Paul C. look D. would
11. The diphthong [əu ] appears in the following word:

A. low B. law C. saw D. bought

12. The diphthong [au] appears in the following word:

A. coal B. call C. loud D. know

13. The diphthong [er] appears in the following word:

A. let B. wait C. rise D. late

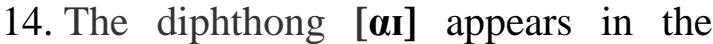
following word:

A. pepper B. rice C. fail D. sail

15. The diphthong [0I] appears in the following word:

A. close B. annoy C. tourist D. file

16. The diphthong [İ] appears in the following word:

A. clear B. noise C. call D. lake

17. The diphthong [uə] appears in the following word:

A. sure B. more C. tower d. flower

18. The vowel sequence (triphthong) [arə] appears in the following word:

A. Tower B. flower C. tired D. coward

19. The vowel sequence (triphthong) [auə] appears in the following word:

A. powerful B. purely C. riot D. tire

20. The vowel sequence (triphthong) [ээә] appears in the following word:

A. bower B. royal C. flyer D. ours 